\section{Kidney \\ Blood Pressure Research}

\title{
Probability of At Least One High Arterial Blood Pressure Measurement in Elderly Patients with Healthy Vascular Aging in Two Years of Follow-Up
}

\author{
Ercilhana G B Freitas ${ }^{a}$ Denis F Souza ${ }^{a}$ Sebastião R Ferreira-Filho ${ }^{a}$ \\ aFederal University of Uberlândia, Uberlândia, Minas Gerais, Brazil
}

\section{Key Words}

Elderly • Vascular health • Prehypertension • Blood pressure

\begin{abstract}
Background/Aims: Elderly patients with normal systemic arterial blood pressure associated with femoral carotid pulse velocity (cf-PWV) less than $7.6 \mathrm{~m} / \mathrm{s}$ and without associated comorbidities are considered to have good vascular health. The aim of the current study was to verify the probability that elderly patients with good vascular health have at least one blood pressure measurement above the different thresholds for systolic blood pressure (120, 130 and $140 \mathrm{mmHg}$ ) during two years of follow-up. Methods: We selected 72 normotensive patients $(<140 / 90 \mathrm{mmHg}$ ) without comorbidities and divided them into group A, with cf-PWV $<7.6 \mathrm{~m} / \mathrm{s}(\mathrm{n}=27 ; 65 \pm 4$ years), and group $B$, with cf-PWV $\geq 7.6 \mathrm{~m} / \mathrm{s}(\mathrm{n}=45 ; 66 \pm 8$ years). These patients were followed for two years and were observed in 3 outpatient visits $(0,12$ and 24 months). At each visit, the brachial pressures were indirectly measured in triplicate, and applanation tonometry was performed. Results: When group A and group B were compared, the odds ratio (OR) of having a systolic pressure measurement $\geq 140 \mathrm{mmHg}$ in two years of follow-up was $0.22(P<0.0001) ; \geq 130 \mathrm{mmHg}$, the OR was $0.49(P<0.0007)$, and $\geq 120$ $\mathrm{mmHg}$, the OR was $0.54(\mathrm{P}<0.001)$. Group $A$ and group $B$ showed increased values of cf-PWV during the two years of follow-up $(P<0.05)$. Changes in the average systolic brachial pressure were not significant during the two years in groups A or B. Conclusion: Vascular health in elderly individuals seems to protect against occasional elevations in systemic arterial pressure.




\section{Kidney Blood Pressure Research}

Ferreira-Filho et al.: Elderly and Healthy Vascular Aging

\section{Introduction}

Vascular health in aging has been defined as carotid-femoral pulse wave velocity (cfPWV) $<7.6 \mathrm{~m} / \mathrm{s}$ (mean \pm SD 2 of a reference group of individuals $<30$ years of age) in combination with the absence of arterial hypertension [1]. This definition is consistent with evidence that increased cf-PWV is an independent predictor of cardiovascular events and improves prediction over traditional risk factors alone, including high blood pressure (BP) [2-4]

Information about longitudinal changes in PWV and SBP parameters in people with good vascular health come from Sardinian data examining the simultaneous trajectories of repeated measures of PWV and SBP, and this analysis demonstrated a remarkable dissociation in the paths of these parameters with advancing age [5]. On the other hand, there are different definitions to consider for the limits of arterial hypertension, especially after reports that lower systolic levels are consistent with a reduction in the morbimortality rate [6]. Thus, the possibility of older adults defined as having good vascular health becoming hypertensive is dependent upon the criteria adopted for the definition of arterial hypertension.

The present study aimed to verify the probability that elderly patients with good vascular health will have at least one blood pressure measurement with levels above different thresholds for systolic blood pressure (120,130 and $140 \mathrm{mmHg}$ ) during two years of follow-up.

\section{Materials and Methods}

The present study is a longitudinal analysis of normotensive elderly patients who have been included in the data bank of Estudo da Velocidade da Onda de Pulso em Idosos de região Urbana no Brasil - Pulse Wave Velocity in the Elderly in a Brazilian Urban Area (EVOPIU), which was a prospective, observational, multiclinic study with a planned four-year follow-up and was designed to correlate cardiovascular endpoints with different groups of elderly hypertensive patients. A total of 1192 elderly individuals were enrolled in EVOPIU, and subjects were followed with laboratory exams and applanation tonometry performed at each medical visit [7]. All the collected data are stored electronically and are the responsibility of the Federal University of Uberlândia, MG, Brazil. EVOPIU was approved by the Research Ethics Committee under CAAE number 37440114.3.0000.5152 and was financed by the Minas Gerais State Agency for Research and Development (FAPEMIG).

\section{Elderly patients with vascular health conditions: Inclusion/Exclusion Criteria}

Data from normotensive patients were extracted from the EVOPIU database according to the following inclusion/exclusion criteria: age $\geq 60$ y.o. and baseline systemic arterial blood pressure $<140 / 90 \mathrm{mmHg}$ without the use of antihypertensive drugs or diuretics. Patients with related comorbidities, such as diabetes mellitus, chronic kidney disease, and known malignant neoplasm, were excluded from this study. After the inclusion and exclusion criteria were applied, a total of 72 normotensive patients constituted our sample. The present article represents a preliminary study of the first two years of follow-up. The patients were examined at baseline (0) and after one (1) and two (2) years of follow up, respectively denoted visits V0, V1 and V2. Patients were separated into two groups: group A, with baseline cf-PWV $<7.6 \mathrm{~m} / \mathrm{s}(\mathrm{n}=27)$, and group B, the control group, with basal cfPWV $\geq 7.6 \mathrm{~m} / \mathrm{s}(\mathrm{n}=45)$.

\section{Biochemical/Hematological Data}

General demographic and clinical data were collected for each subject. Serum levels of uric acid, urea, creatinine, blood glucose, and the lipid profile were assessed using colorimetric methods (Cobas 6000; Roche Hitachi $\AA^{\circ}$, Brazil, As $2400 ®$ (Roche $®$, Brazil), whereas hematological examination was performed with a Sysmex XED-2100@, Sysmed Brazil, JP. Patients were considered to have hypercholesterolemia when they had total fasting cholesterol $>200 \mathrm{mg} / \mathrm{dL}$, HDL cholesterol $<40 \mathrm{mg} / \mathrm{dL}$, triglycerides $>190 \mathrm{mg} / \mathrm{dL}$, or used statins; diabetes mellitus was defined as fasting plasma glucose $\geq 126 \mathrm{mg} / \mathrm{dL}$ or when patients were 


\section{Kidney Blood Pressure Research}

Ferreira-Filho et al.: Elderly and Healthy Vascular Aging

using insulin/oral hypoglycemic drugs; and chronic kidney disease was defined as a glomerular filtration rate $<60 \mathrm{ml} / \mathrm{min} / \mathrm{m}^{2}$ and urinary creatinine/protein $<0.2 \mathrm{mg} / \mathrm{g}$.

Blood Pressure Measurements- Brachial (bBP)

After 10 min of rest, brachial systemic blood pressure was assessed in a seated position three consecutive times at 3-min intervals labeled the first, second and third blood pressure measurements at each medical visit. For the first two measurements, an automatic digital oscillometric blood pressure (BP) device (HE 7200 Intelli-Sense Omron Hem®, Brazil) was used; the third measurement was performed with a SphygmoCor ${ }^{\circledR}$, Sydney, AU. We used triplicate measurements of blood pressure, considering each one of the three measures separately (named the first, second and third measurements) and reporting the arithmetic mean of the three measurements. A total of 603 blood pressure measurements were taken from the 72 patients, who attended three medical visits in two years of follow up. For analysis, we considered three different cutoffs for the definition of elevated blood pressure or hypertension status: 120, 130 and $140 \mathrm{mmHg}$.

\section{Central blood pressure, $P W V$, and AIX}

Central BP values, carotid-femoral pulse wave velocity (cf-PWV) and the aortic augmentation index (AIx) were obtained by direct-method applanation tonometry with a SphygmoCor ${ }^{\circledR}$ XCEL device, model EM4C (AtCor Medical, Sydney, Australia); cf-PWV was measured in meters per second, with the patient in a supine position. The AIx was automatically adjusted for a heart rate of $75 \mathrm{bpm}$ since the heart rate is an important modifier of AIx.

\section{Statistical analysis}

We assessed the normality of the data set using Skewness/Kurtosis tests. For comparisons of two samples with a parametric distribution, Student's t-test was used, and for nonparametric data, a Wilcoxon rank-sum (Mann-Whitney) test was used with the data being shown as the mean $+/$ - standard error and median (p50) +/- interquartile interval (IQR), respectively. For comparison of three or more normal variables, analysis of variance (ANOVA) was performed with Bonferroni posttest adjustment, and for nonparametric variables, the Kruskal-Wallis equality-of-populations rank test was used. The cf-PWV values were not adjusted for sex, age or mean arterial pressure (MAP) because of the small number of participants in each group. The odds ratio was calculated using a $2 \times 2$ table, and chi-square and Fisher's exact test were applied. The null hypothesis is as follows: the group with good vascular health would have all arterial pressure measurements at all medical visits below normal values. The alternative hypothesis is as follows: at least one of the pressure measurements would be above normal values during medical appointments. Significance was set at $\mathrm{p}<0.05$ in all analyses. The STATA 15.1 and Prisma 5.0 software programs were used for statistical analyses.

\section{Results}

Elderly patients who met the criteria for vascular health corresponded to $2.2 \%$ (A) and the control group (B) to 3.7\% of the EVOPIU database. Table 1 shows the clinical and laboratory characteristics of normotensive patients with cfPWV $<7.6 \mathrm{~m} / \mathrm{s}$ (A) and with cf-PWV $\geq 7.6 \mathrm{~m} / \mathrm{s}$ (B). Table 1 shows the cfPWV values adjusted by brachial blood arterial pressure, gender and age. Table 2 shows the probability for the patients to have at least one high blood pressure reading in a medical visit in two years of follow-up according to the different thresholds for systolic blood pressure. Fig. 1 demonstrates the cf-PWV values without adjustments in the first, second and third medical visits for groups A and B. Fig. 2 shows the systolic blood pressure box plot for each visit for both groups (Table 1). Fourteen patients did not continue the study for 24 months: 2 died from pneumonia (group A), and 12 were followed only by telephone contact. These patients did not have their data included in this study. 


\section{Kidney Blood Pressure Research}

Table 1. Clinical and Laboratory Characteristics of the Patients by Group and Medical Visit. Mean \pm SD; Median (Iq); SBP, DBP, PP, MAP: Systolic, Diastolic; Pulse Pressure and Mean Arterial blood pressure; b: brachial, c: central; cf-PWV: carotid femoral Pulse Wave Velocity; Aix: augmentation Index; HDL and LDL High and Low density cholesterol; ${ }^{* *} \mathrm{P}<0.05$ A versus $\mathrm{B},{ }^{\wedge}$ : $\mathrm{P}<0.05$ intergroup.

\begin{tabular}{|c|c|c|c|c|c|c|}
\hline \multirow{4}{*}{ Parameter } & \multicolumn{6}{|c|}{ Visits (months) } \\
\hline & \multicolumn{2}{|c|}{0} & \multicolumn{2}{|c|}{12} & \multicolumn{2}{|c|}{24} \\
\hline & & & & & & \\
\hline & $A(n: 27)$ & $B(n: 45)$ & $\mathrm{A}(\mathrm{n}: 27)$ & B (n:44) & $A(n: 21)$ & $B(n: 37)$ \\
\hline Age (years) & $65(4)$ & $66(8)$ & $66(4)$ & $67(7)$ & $66(3.5)$ & $66(7)$ \\
\hline HR (bpm) & $72(12)$ & $71(16)$ & $72(13)$ & $68(12)$ & $72(11)$ & $72(17)$ \\
\hline Gender (F/M) (\%) & $74 / 26$ & $45 / 55$ & $74 / 26$ & $46 / 54$ & $72 / 28$ & $46 / 54$ \\
\hline BMI $(\mathrm{Kg} / \mathrm{m} 2)$ & $24.8(8.1)$ & $26.2(4.7)$ & $25.6(9.2)$ & $26.2(5.3)$ & $25.5(10.4)$ & $25.6(17.3)$ \\
\hline Abdominal waist $(\mathrm{cm})$ & $87.9 \pm 15.5$ & $91.6 \pm 12.9$ & $89.8 \pm 12.7$ & $94.3 \pm 11.1$ & $93.3 \pm 13.9$ & $93.3 \pm 12.0$ \\
\hline \multicolumn{7}{|l|}{ Race (\%) } \\
\hline White & 4 & 14 & 5 & 14 & 9 & 8 \\
\hline Non White & 96 & 86 & 95 & 86 & 91 & 92 \\
\hline \multicolumn{7}{|l|}{ Blood Presure (mmHg) } \\
\hline bSBP & $118.4 \pm 9.3$ & $121.2 \pm 6.8$ & $121.0 \pm 14.1$ & $125 \pm 12.2$ & $119.2 \pm 10.8$ & $119.5 \pm 12.3$ \\
\hline bDBP & $69.2 \pm 7.6$ & $71.0 \pm 6.6$ & $70.2 \pm 8.8$ & $72.8 \pm 8.7$ & $69.8 \pm 7.6$ & $70.0 \pm 7.4$ \\
\hline bPP & $47(18)$ & $49(12)$ & $50(11)$ & $51(11)$ & $48(13)$ & $49(13)$ \\
\hline bMAP & $85.5 \pm 6.4$ & $87.7 \pm 5.6$ & $86.9 \pm 9.3$ & $90.1 \pm 9.3$ & $86.3 \pm 7.0$ & $86.5 \pm 8.4$ \\
\hline cSBP & $111 \pm 10.5$ & $115 \pm 7.5$ & $116 \pm 9.1$ & $118 \pm 11.7$ & $115 \pm 12.0$ & $112 \pm 11.8$ \\
\hline $\mathrm{cDBP}$ & $72.8 \pm 7.1$ & $76.4 \pm 8.1^{* *}$ & $77.4 \pm 9.1$ & $78.7 \pm 8.5$ & $77.2 \pm 6.9$ & $75.9 \pm 9.7$ \\
\hline cPP & $39(16)$ & $38(9)$ & $38(13)$ & $39(12)$ & $37(12)$ & $34(13)$ \\
\hline cMAP & $88.4 \pm 7.1$ & $91.8 \pm 7.4^{* *}$ & $92.7 \pm 8.3$ & $93.9 \pm 9.2$ & $92.8 \pm 90.9$ & $90.9 \pm 9.9$ \\
\hline Hypertensive Patients (n)(\%) & 0 & 0 & 0 & 5 (13.5) & 0 & $8(21.6)$ \\
\hline \multicolumn{7}{|l|}{ Tonometry } \\
\hline $\mathrm{cf}-\mathrm{PWV}(\mathrm{m} / \mathrm{s})$ & $6.9(1.1)$ & $8.6(1.4)^{* *}$ & $7.2(1.4)$ & $9.3(2.3)^{* *}$ & $8.4(2.1)^{\wedge}$ & $11(2.6)^{* * \wedge}$ \\
\hline Aix $(\%)$ & $36.5 \pm 16.3$ & $28.1 \pm 16.0^{* *}$ & $34.7 \pm 16.7$ & $26.3 \pm 10.9^{* *}$ & $26.5 \pm 0.2$ & $26.0 \pm 17.4$ \\
\hline \multicolumn{7}{|l|}{ Laboratory } \\
\hline Total cholesterol (mg\%) & $197(30)$ & $203(45)$ & $212(20)$ & 199 (63.5) & $204(34)$ & $185(68)$ \\
\hline HDL (mg\%) & $50(8)$ & $53(20)$ & $54(15.5)$ & $49(15)$ & $51(14)$ & $47(15.5)$ \\
\hline LDL (mg\%) & $117(52.3)$ & $118(39)$ & $131.5(24.9)$ & $120(52.6)$ & $134(35.7)$ & $120(49.9)$ \\
\hline Triglycerides & $108(63)$ & $110(93)$ & $122(45)$ & $108(53)$ & $96(46)$ & $107(38.5)$ \\
\hline Glucose (mg\%) & $93(9.1)$ & $92(14.8)$ & $89(9)$ & $91(17.5)$ & $85(12)$ & $85(24)$ \\
\hline Uric acid (mg\%) & $4.9(1.1)$ & $5(1.8)$ & $4.5(0.9)$ & $5.1(2.1)$ & $4.8(0.7)$ & $5.4(1.6)$ \\
\hline Creatinine (mg\%) & $0.6 \pm 0.1$ & $0.8 \pm 0.1^{* *}$ & $0.7 \pm 0.1$ & $0.9 \pm 0.1^{* *}$ & $0.9 \pm 0.2$ & $0.8 \pm 0.1^{* *}$ \\
\hline Hematocrit $(\%)$ & $41.5(4.9)$ & $42.7(3.7)$ & $42.2(5.7)$ & $42.7(4.2)$ & $42.3(3.7)$ & $42.7(5.2)$ \\
\hline Hemoglobin (\%) & $13.8(1.5)$ & $14.3(1.4)$ & $14.2(2.5)$ & $14.2(1.8)$ & $13.6(1.1)$ & $14.0(1.7)$ \\
\hline Urinary Protein/creatinine & $0.12 \pm 0.01$ & $0.13 \pm 0.01$ & $0.10 \pm 0.01$ & $0.14 \pm 0.01$ & $0.12 \pm 0.01$ & $0.13 \pm 0.01$ \\
\hline
\end{tabular}

Table 2. Pulse Wave Velocity and chance of high Systemic Blood Pressure in Two Years of Follow-up. SBPM*: Systemic Blood Pressure measurements of Systolic (SBP), Diastolic (DBP) and Pulse Pressure (PP);N*: number of SBPM by group.

\begin{tabular}{|c|c|c|c|c|c|c|}
\hline \multirow{3}{*}{ Variable } & \multicolumn{4}{|c|}{ SBPM } & \multicolumn{2}{|l|}{ Odds Ratio } \\
\hline & \multicolumn{2}{|c|}{ A group } & \multicolumn{2}{|c|}{ B group } & \multirow[b]{2}{*}{ [95\% Conf. Interval] } & \multirow[t]{2}{*}{$P$ value } \\
\hline & $\mathrm{N}^{*}$ & $\%$ & $\mathrm{~N}^{*}$ & $\%$ & & \\
\hline \multicolumn{7}{|c|}{ SBP (mmHg) } \\
\hline$<140$ & 182 & 96.3 & 353 & 85.2 & 1 & \\
\hline$>=140$ & 7 & 3.7 & 61 & 14.8 & $0.2256(0.0843-0.5011)$ & 0,0001 \\
\hline$<130$ & 152 & 80.4 & 277 & 66.9 & 1 & \\
\hline$>=130$ & 37 & 19.6 & 137 & 33.1 & $0.4921(0.3161-0.7554)$ & 0,0007 \\
\hline$<120$ & 88 & 46.6 & 254 & 61.3 & 1 & \\
\hline$>=120$ & 101 & 53.4 & 160 & 38.7 & $0.5488(0.3818-0.7888)$ & 0,001 \\
\hline \multicolumn{7}{|c|}{ DBP (mmHg) } \\
\hline$<90$ & 188 & 99.5 & 375 & 90.5 & 1 & \\
\hline$>=90$ & 1 & 0.5 & 39 & 9.5 & $0.0511(0.0012-0.3080)$ & $<0.0001$ \\
\hline$<80$ & 164 & 86.7 & 312 & 75.3 & 1 & \\
\hline$>=80$ & 25 & 13.3 & 102 & 24.7 & $0.4662(0.2773-0.7685)$ & 0,0014 \\
\hline \multicolumn{7}{|c|}{ PP (mmHg) } \\
\hline$<50$ & 98 & 51.8 & 191 & 46.1 & 1 & \\
\hline$>=50$ & 91 & 48.2 & 223 & 53.9 & $0.8546(0.6078-1.2012)$ & 0,3463 \\
\hline
\end{tabular}




\section{Kidney \\ Blood Pressure \\ Research}

Fig. 1. Unadjusted values of cf-PWV in two groups of normotensive elderly patients with $\mathrm{cf}-\mathrm{PWV}<7.6$ (A) and $\geq 7.6 \mathrm{~m} / \mathrm{s}$ over two years of follow-up.

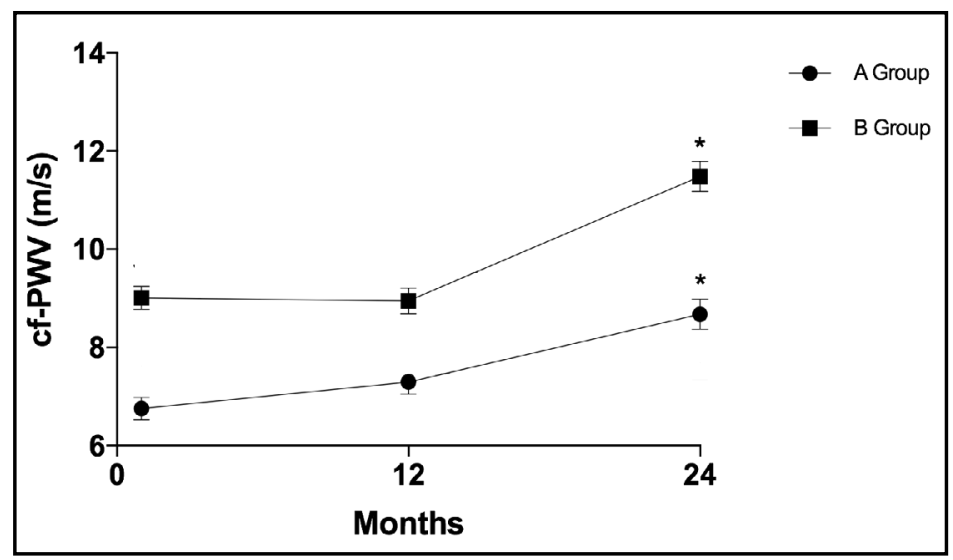

Fig. 2. Box-plot showing the values of the first, second and third systolic pressure measurements $(n=603)$ during three outpatient visits of normotensive elderly patients in groups A and B. Dashed lines represent the different cutoffs.

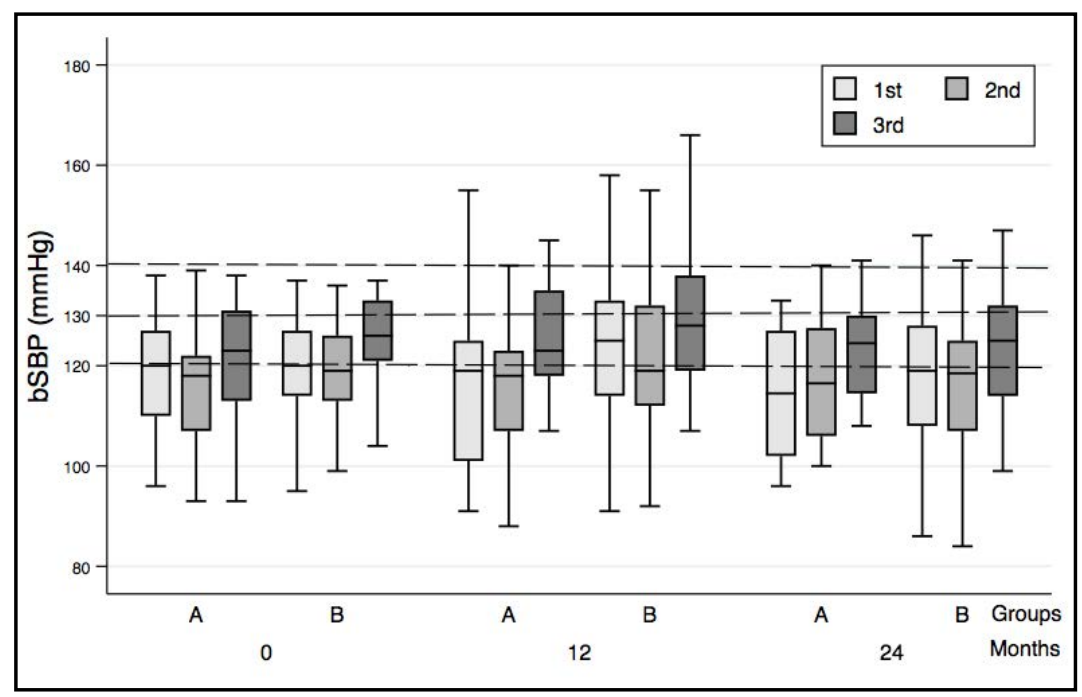

\section{Discussion}

Our study showed that elderly patients in a healthy vascular condition have a low chance of becoming hypertensive during two years of follow up. Finding older adults who meet the criteria necessary to diagnose good vascular health is not an easy task. Thus, $2.1 \%$ of the 1192 patients participating in EVOPIU could be included in these criteria using a cutoff for systolic blood pressure $<140 \mathrm{mmHg}$. Elderly patients belonging to this select group of individuals did not have diabetes, had no other comorbidities common to the elderly, and did not use any antihypertensive medications. On the other hand, normotensive patients, without comorbidities but with a cf-PWV $>7.6 \mathrm{~m} / \mathrm{s}$, were also not a frequent finding in our database, representing only $4.0 \%$ of the sample total.

When we compared the cf-PWV of both groups from V0 to V2, we found that the cf-PWV of group B remained significantly higher than that observed in group A.

If increases in cfPWV are associated with increases in vascular stiffness, one would suppose that group B had more vascular damage than group A and did not yet show arterial hypertension. Although arterial stiffness has long been considered to be a complication of hypertension, there is growing evidence that arterial stiffening can precede the increase in SBP, and an elevation of SBP further augments arterial stiffness [8-11].

Our study also demonstrated the cfPWV behavior in elderly patients with low and high cfPWV during two years of follow-up (Fig. 1). In the unadjusted model, the cfPWV increased 


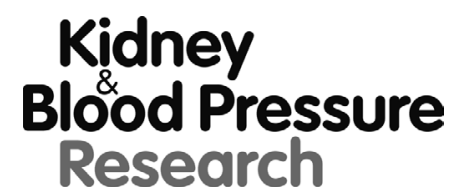

Kidney Blood Press Res 2018;43:1765-1771

\begin{tabular}{|l|l|}
\hline DOI: $10.1159 / 000495634$ & (c) 2018 The Author(s). Published by S. Karger AG, Basel \\
\hline
\end{tabular}

Published online: 1 December 2018 www.karger.com/kbr

Ferreira-Filho et al.: Elderly and Healthy Vascular Aging

after two years in both groups, but only group B showed eight hypertensive patients at 24 months (Table 1). These findings indicate that values of cfPWV $>=7.6 \mathrm{~m} / \mathrm{s}$ may be associated with so-called prehypertension.

It was interesting to note that the average values of arterial pressures obtained by triplicate measurements did not change during the follow-up examinations of both groups, which did not mean that any of the measures did not exceed the cutoff values established for the diagnosis of arterial hypertension. Table 2 shows that for group A, the chance of having at least one arterial systolic pressure measurement higher than $140 \mathrm{mmHg}$ is $77.7 \%$ lower than the risk for group B. For the cutoff of $130 \mathrm{mmHg}$, group A has a $51 \%$ lower chance than group B, and for a cutoff of $120 \mathrm{mmHg}$, group $A$ has a $46 \%$ lower risk than group $B$. The data show that the lower the cutoff value for systolic blood pressure is, the lower the difference in the risk of individuals with and without vascular health to become hypertensive. Another explanation for the same data is shown in Fig. 2. As we can see, the systolic variations above 140, 130 and $120 \mathrm{mmHg}$ are more notable in group B. For diastolic pressures, the same occurred, demonstrating that the elderly patients who fit within the vascular health criteria with any cutoff are less likely to have at least one high blood pressure measurement for two years than those in group B.

It can be argued that only a measure of BP above the stipulated cutoff would not have clinical significance, but many studies are proving that pressure-ability cannot be called physiological, and these oscillatory levels of blood pressure represent damage to target organs $[12,13]$. It is interesting to note that the widening of the pulse pressure, considered one of the indicators of vascular rigidity [14], did not show different odds in the two groups studied. The increase in bPP occurred similarly between the high- and low-cfPWV groups. A follow-up time greater than that used in our study may be able to reveal the outcomes for the elderly patients in both groups.

An SBP target $<130 \mathrm{mmHg}$ has been proposed as reasonable in primary prevention with a low overall and cardiovascular risk [15]. Prehypertension is also an independent predictor of decreased glomerular filtration rate in the general population, with the effect being more pronounced in the elderly [16]. If systolic values higher than $130 \mathrm{mmHg}$ are classified as a prehypertensive condition, the elderly with a cf-PWV $<7.6 \mathrm{~m} / \mathrm{s}$ have a $51 \%$ lower risk of developing prehypertension. Even with lower limits for the diagnosis of prehypertension, elderly patients with vascular health are more protected from higher systolic and diastolic levels over two years (Table 2).

Other parameters obtained by tonometry show different values for Aix, but the number of female individuals in group A is proportionally higher than that in group B, justifying this finding [17]. The same reasoning applies to the different serum creatinine levels in both groups. We also did not find different values for the central pressures between the groups over two years of follow-up, nor for the laboratory data obtained. As limitations of our study, we would point out the small number of participants in each group and the blood pressure measurements being performed in the office. The ambulatory blood pressure measurement (ABPM) is perhaps more appropriate for this type of study.

In conclusion, patients with good vascular health seem to be better protected against occasional elevations in systemic arterial pressure than other groups without these conditions. Longer-term studies should be performed to verify the cardiovascular outcomes of these patients.

\section{Acknowledgements}

FAPEMIG (Fundação de Amparo à Pesquisa do Estado de Minas Gerais). 


\section{Kidney \\ Blood Pressure Research}

Ferreira-Filho et al.: Elderly and Healthy Vascular Aging

\section{Disclosure Statement}

No conflicts of interest exists.

\section{References}

1 Niiranen TJ, Lyass A, Larson MG, Hamburg NM, Benjamin EJ, Mitchell GF, Vasan RS: Prevalence, Correlates, and Prognosis of Healthy Vascular Aging in a Western Community-Dwelling Cohort: The Framingham Heart Study. Hypertension 2017;70:267-274.

-2 Ben-Shlomo Y, Spears M, Boustred C, May M, Anderson SG, Benjamin EJ, Boutouyrie P, Cameron J, Chen CH, Cruickshank JK, Hwang SJ, Lakatta EG, Laurent S, Maldonado J, Mitchell GF, Najjar SS, Newman AB, Ohishi M, Pannier B, Pereira T, et al.: Aortic pulse wave velocity improves cardiovascular event prediction: an individual participant meta-analysis of prospective observational data from 17, 635 subjects. J Am Coll Cardiol 2014;63:636-646.

3 Vlachopoulos C, Aznaouridis K, Stefanadis C: Prediction of cardiovascular events and all-cause mortality with arterial stiffness: a systematic review and meta-analysis. J Am Coll Cardiol 2010;55:1318-1327.

- Willum-Hansen T, Staessen JA, Torp-Pedersen C, Rasmussen S, Thijs L, Ibsen H, Jeppesen J: Prognostic value of aortic pulse wave velocity as index of arterial stiffness in the general population. Circulation 2006;113:664-670.

5 Scuteri A, Morrell CH, Orru M, Strait JB, Tarasov KV, Ferreli LA, Loi F, Pilia MG, Delitala A, Spurgeon H, Najjar SS, AlGhatrif M, Lakatta EG: Longitudinal perspective on the conundrum of central arterial stiffness, blood pressure, and aging. Hypertension 2014;64:1219-1227.

-6 Group SR, Wright JT Jr, Williamson JD, Whelton PK, Snyder JK, Sink KM, Rocco MV, Reboussin DM, Rahman M, Oparil S, Lewis CE, Kimmel PL, Johnson KC, Goff DC Jr, Fine LJ, Cutler JA, Cushman WC, Cheung AK, Ambrosius WT: A Randomized Trial of Intensive versus Standard Blood-Pressure Control. N Engl J Med 2015;373:2103-2116.

7 Mendonca GS, Souza DF, Brunelli AC, Oliveira CI, Freitas EGB, Lacerda GN, Dorneles MC, Peixoto AJ, Ferreira-Filho SR: Arterial stiffness in elderly patients with normotension and hypertension in Brazil. J Clin Hypertens (Greenwich) 2018;20:1285-1293.

8 Mitchell GF: Arterial stiffness and hypertension: chicken or egg? Hypertension 2014;64:210-214.

-9 Kaess BM, Rong J, Larson MG, Hamburg NM, Vita JA, Levy D, Benjamin EJ, Vasan RS, Mitchell GF: Aortic stiffness, blood pressure progression, and incident hypertension. JAMA 2012;308:875-881.

10 Weisbrod RM, Shiang T, Al Sayah L, Fry JL, Bajpai S, Reinhart-King CA, Lob HE, Santhanam L, Mitchell G, Cohen RA, Seta F: Arterial stiffening precedes systolic hypertension in diet-induced obesity. Hypertension 2013;62:1105-1110.

11 Nowak KL, Rossman MJ, Chonchol M, Seals DR: Strategies for Achieving Healthy Vascular Aging. Hypertension 2018;71:389-402.

12 Yokota K, Fukuda M, Matsui Y, Hoshide S, Shimada K, Kario K: Impact of visit-to-visit variability of blood pressure on deterioration of renal function in patients with non-diabetic chronic kidney disease. Hypertens Res 2013;36:151-157.

13 Aznaouridis K, Vlachopoulos C, Masoura K, Pietri P, Vyssoulis G, Ioakeimidis N, Stefanadis C, Tousoulis D: Office blood pressure is a predictor of aortic elastic properties and urinary protein excretion in subjects with white coat hypertension. Int J Cardiol 2016;203:98-103.

14 Steppan J, Barodka V, Berkowitz DE, Nyhan D: Vascular stiffness and increased pulse pressure in the aging cardiovascular system. Cardiol Res Pract 2011;2011:263585.

15 Tsioufis C, Thomopoulos C, Kreutz R: Treatment Thresholds and Targets in Hypertension: Different Readings of the Same Evidence? Hypertension 2018;71:966-968.

16 Garofalo C, Borrelli S, Pacilio M, Minutolo R, Chiodini P, De Nicola L, Conte G: Hypertension and Prehypertension and Prediction of Development of Decreased Estimated GFR in the General Population: A Meta-analysis of Cohort Studies. Am J Kidney Dis 2016;67:89-97.

17 Coutinho T, Borlaug BA, Pellikka PA, Turner ST, Kullo IJ: Sex differences in arterial stiffness and ventriculararterial interactions. J Am Coll Cardiol 2013;61:96-103. 